\title{
REFLEXÕES ACERCA DAS INFECÇÕES HOSPITALARES ÀS PORTAS DO TERCEIRO MILÊNIO*
}

\author{
REFLECTIONS ABOUT CROSS INFECTIONS IN THE TRANSITION TO THE THIRD MILLENIUM
}

\author{
Denise de Andrade ${ }^{1}$ \& Emília L. S. Angerami²
}

\begin{abstract}
1,2 Docente do Departamento de Enfermagem Geral e Especializada da Escola de Enfermagem de Ribeirão Preto da Universidade de São Paulo.

CorRespondÊncia: Denise de Andrade.Departamento de Enfermagem Geral e Especializada da Escola de Enfermagem de Ribeirão Preto da USP - Av Bandeirantes, 3.900. CEP: 14.040-902 Ribeirão Preto - São Paulo.
\end{abstract}

ANDRADE D \& ANGERAMI ELS. Reflexões acerca das infecções hospitalares às portas do terceiro milênio. Medicina, Ribeirão Preto, 32: 492-497, out./dez. 1999.

RESUMO: O presente estudo tem como meta primordial desencadear reflexões ou sensibilizar os profissionais de saúde no que tange às infecções hospitalares. As autoras apresentam uma síntese de fatos relevantes, associados à temática, bem como das disposições normativas de prevenção e de controle das infecções hospitalares no Brasil. Em seguida, mostram e analisam as perspectivas para o futuro. Alertam para a necessidade de uma pluralidade de ações, estruturada em recursos humanos e materiais, e reforçam a necessidade de se redimensionar a problemática das referidas infecções ao âmbito mais amplo da organização do sistema de saúde. Também, reforçam alguns cuidados: o uso indiscriminado de antimicrobianos, internações desnecessárias e por tempo prolongado. Sem dúvida, que a conscientização e a mudança de comportamento são condutas essenciais, frente a esse importante problema médico, social e econômico.

UNITERMOS: Infecção Hospitalar. Assepsia. Controle de Infecções.

\section{INTRODUÇÃO}

Às portas do século XXI, um novo cenário na medicina é observado, em consequiência do grande avanço científico e tecnológico, da globalização das relações humanas, desencadeada pelas conquistas nos setores de telecomunicação e de informática. No entanto, o reconhecimento, cada vez maior, de novos agentes infecciosos e o ressurgimento de infecções, que até pouco tempo estavam presumivelmente controladas, também caracterizam esta nova fase. Acresce-se a estes problemas o número cada vez maior de agentes infecciosos que adquiriram resistências a uma série de drogas antimicrobianas, como conseqüência de um processo de seleção gerado pelo uso desenfre- ado e inadequado das respectivas drogas com ações cada vez maiores ${ }^{(1)}$.

Este estudo tem como objetivo pontuar alguns aspectos, importantes, relativos às infecções hospitalares, com vistas a desencadear reflexões e a sensibilizar os profissionais de saúde. A escolha da referida temática está relacionada a muitos fatores, dentre eles, por considerarmos uma das problemáticas mais importantes, principalmente, para a comunidade médico-hospitalar.

Acreditamos que o assunto, infecção hospitalar, precisa de ser abordado não de forma conformista, mas, reflexiva e crítica, para que possamos tomar importantes decisões, o que contribuirá para um futuro menos árido. 
Em termos gerais, as infecções hospitalares não só elevam as taxas de morbimortalidade, como, também, ampliam o tempo de permanência dos pacientes nos hospitais, com o conseqüente aumento do custo do tratamento e menor utilização dos leitos hospitalares. Quando falamos em infecção hospitalar, não se podem ocultar as outras repercussões, as quais extrapolam os custos devido ao aumento do período de internação com o tratamento adicional. Há que se considerar, também, a interrupção da vida produtiva do indivíduo, assim como a possibilidade de ações legais requeridas contra o hospital e profissionais, pelo fato de, o paciente julgar-se prejudicado em sua saúde devido às intervenções hospitalares iatrogênicas ${ }^{(2)}$.

\section{INFECÇÃO HOSPITALAR: UMA BREVE RETROSPECTIVA HISTÓRICA}

O hospital, como designativo de instituição para atendimento aos doentes, vem sofrendo sérias modificações à medida que estudos vão sendo realizados, oferecendo, assim, contribuições que possam melhorar sua condição.

Durante séculos, as pessoas que adoeciam eram isoladas em locais sombrios, úmidos, sem luz natural, sem cuidado higiênicos e dietéticos. A exemplo dessa realidade, destacam-se os sanatórios para hansenianos, da Idade Média, que viriam facilitar a difusão de doenças transmissíveis, podendo-se situar a origem das infecções hospitalares nesse período.

No decorrer do tempo, apesar de ainda não se dispor dos conhecimentos da Microbiologia, foi-se percebendo a associação entre hospitalização e infecção. Na metade do século passado, surge a expressão "hospitalismo", para designar as patologias adquiridas no hospital.

O conhecimento vigente desencadeava a formação de diversas correntes que tentavam explicar e intervir na transmissão das doenças, algumas vezes com sucesso. Isto pode ser evidenciado através dos esforços de estudiosos que, mesmo sem conhecer o mundo dos organismos microscópicos, valorizavam a higiene pessoal e ambiental.

As transformações ocorridas, sobretudo no século XVIII, possibilitaram que os hospitais exercessem uma ação terapêutica mais efetiva, em comparação com as das épocas anteriores, pois, iniciou-se o questionamento sobre as condições insalubres, a promiscuidade e a mistura dos corpos em camas coleti- vas, o que favorecia toda ordem de contágio. Assim, o início das práticas de controle da transmissão das doenças contagiosas surgiu a partir desse século, período em que ocorre a mudança da concepção de hospital como um local onde as pessoas eram internadas para morrerem, para um local de cura e medicalização.

Vale destacar aqui a atuação de Semmelweis, em 1847, que tornou compulsória a lavagem das mãos com água clorada, para todos os médicos, estudantes de medicina e pessoal de enfermagem, reduzindo a mortalidade materna por febre puerperal de $12,2 \%$ para $2,4 \%$, logo no primeiro mês de intervenção ${ }^{(3)}$.

A situação de insalubridade dentro dos hospitais vai persistir até a metade do século XIX, quando esse cenário começa a se modificar com o estabelecimento da bacteriologia, por Pasteur, e os conceitos de assepsia, por Lister.

Muitos investimentos foram executados na busca insana por medidas de controle da contaminação microbiana, entre os quais, citamos os de Joseph Lister, em 1865, que, preocupado com a possibilidade de infecção nas suas cirurgias, utilizava um dispositivo para pulverizar ácido fênico no ar da sala cirúrgica (substância bastante irritante para o paciente e seus assistentes), passando, posteriormente, a investir na lavagem das mãos, desinfecção de instrumentais e campos cirúrgicos.

É importante registrar que a enfermagem vem assumindo as funções de prevenção e controle da contaminação do ambiente hospitalar, desde o desempenho de Florence Nightingale. No final do século XIX, Florence utilizava a limpeza, o isolamento, a individualização do cuidado, dieta adequada, diminuição do número de leitos por enfermaria e a diminuição da circulação de pessoas estranhas ao serviço, como forma de reduzir os efeitos negativos do meio hospitalar sobre o paciente. Ela não mediu esforços, apesar do conhecimento vigente, no sentido de estimular a observância da cadeia asséptica, preocupando-se em evitar a propagação das infecções, ou seja, reduzir as agressões microbiológicas ao organismo dos pacientes ${ }^{(4)}$.

A partir desses investimentos, as conquistas no campo da bacteriologia, para o controle da contaminação ambiental, tornaram-se uma constante, visando possibilitar êxito nas intervenções médicas e criando um mundo "asséptico".

Com o estabelecimento do conceito das infecções adquiridas nos hospitais, foi possível a implementação de intervenções que almejavam o controle des- 
sa problemática. A infecção passa a ser caracterizada como um desequilíbrio no sistema parasita - hospedeiro - ambiente, por conseqüência, do aumento da patogenicidade do parasita em relação aos mecanismos de defesa do hospedeiro, ou pela diminuição da capacidade normal de defesa antiinfecciosa do hospedeiro, em relação a patogenicidade normal do parasita.

Quanto aos fatores de risco às infecções hospitalares, eles podem ser divididos em intrínsecos e extrínsecos. Consideramos fator de risco intrínseco aquelas características relacionadas, especificamente, ao paciente/hospedeiro, ou seja, tipo e gravidade da doença de base, condição nutricional, idade, uso de drogas imunossupressoras, dentre outras.

Já o risco extrínseco está relacionado ao meio ambiente inanimado (superfícies, artigos médico-hospitalares ou equipamentos), agressões ao hospedeiro (procedimentos invasivos), e a qualidade do cuidado dispensado ao paciente pela equipe. Couto \& Pedrosa, $1997^{(5)}$ citam que: o meio ambiente hospitalar não causa infecção e, sim, os deslizes com a qualidade dos cuidados que ao paciente devem ser dispensados. Ain$\mathrm{da}$, os autores sugerem que, em se tratando de infecção hospitalar, devemos, constantemente, investigar e questionar:

Variaram os critérios de diagnósticos?

Houve variação na técnica de vigilância epidemiológica?

Variaram os riscos intrínsecos?

Variaram os riscos extrínsecos (meio, quantidade de agressão, qualidade do cuidado)?

Conseqüentemente, temos que as práticas, recomendadas para o controle das infecções adquiridas nos hospitais, valorizam claramente os fatores relacionados ao ambiente e aos procedimentos em geral. Nos fatores ambientais, predomina a preocupação com a estrutura física hospitalar, as medidas de higiene e de processamento dos artigos médico - hospitalares.

Nesse sentido, especificamente, para o processamento dos artigos hospitalares, necessário se faz classificá-los conforme o potencial de transmissão de infecções, ou seja, críticos, semicríticos ou não críti$\cos { }^{(6)}$.

Tal classificação tem a finalidade de auxiliar, de maneira racional e lógica, a escolha do procedimento antimicrobiano a ser empregado. Isto é, dependendo do tipo de contaminação e da natureza do material, a recomendação pode envolver desde a lava- gem manual até o mais sofisticado processo de esterilização.

Nesta perspectiva, é importante destacar que a prevenção da infecção hospitalar, relacionada ao ambiente, depende dos meios de controle dos germes patogênicos, da aplicação de medidas de assepsia e do tratamento que se dá ao material e ambientes contaminados por eles. Não se pode ficar alheio ao fato de que o ambiente hospitalar pode oferecer condições excelentes para a propagação de microrganismos, mesmo em meio a desinfetantes, anti-sépticos, antibióticos e quimioterápicos, e que os pacientes podem ser susceptíveis porque estão com seus mecanismos imunológicos abalados pela própria doença, agressões cirúrgicas ou acidentais que abrem caminhos para a penetração microbiana.

Por outro lado, [Oliveira, 1982(7)] levanta a questão de que a alta tecnologia representada pelos equipamentos, aparelhagens e dispositivos, vem proporcionando aos profissionais de saúde maior descuido, falta de atenção na observância dos princípios higiênicos básicos, além do uso indiscriminado de medicamentos antimicrobianos, anti-sépticos e desinfetantes.

\subsection{As disposições normativas no Brasil relati- vas às medidas de prevenção e controle das infecções hospitalares}

A infecção hospitalar, institucional ou nosocomial, é definida, no Brasil, como toda aquela infecção adquirida após a admissão do paciente em um hospital, e que se manifeste durante a internação ou após a alta, quando puder ser relacionada com a internação ou com os procedimentos hospitalares, conforme a Portaria n. ${ }^{\circ} 2616$ de 12 de maio de $1998^{(8)}$.

De uma maneira geral, o reconhecimento das infecções hospitalares não ficou somente na realização de estudos e publicações. Surgiram movimentos de sensibilização ao problema, visando ao estabelecimento de iniciativas concretas de controle. Neste percurso, não apenas foram realizados alguns eventos sobre o assunto, como criadas as primeiras Comissões de Controle de Infecção Hospitalar (CCIH) em alguns hospitais privados e públicos.

Assim sendo, a primeira intervenção governamental no Brasil, para o controle das infecções hospitalares, aconteceu com a emissão da Portaria no 196 de 24 de junho de 1983, pelo Ministério da Saúde onde “... todos os hospitais do País deverão manter 
Comissão de Controle Infecção Hospitalar (CCIH) independentemente da natureza da entidade mantenedora". Essa mesma Portaria estabelecia as indicações para organização e formação do processo de trabalho da comissão $(\mathrm{CCIH})$, caracterizando seus agentes e as suas atividades, como, também, os critérios para identificação e o diagnóstico dos diferentes tipos de infecções hospitalares. É importante ressaltar que as normas para seleção de germicidas, também, estão incluídas nessa portaria ${ }^{(9)}$.

Daí por diante, a organização de ações para o controle das infecções hospitalares, em nível ministerial, sofreu várias modificações, revogando portarias já existentes e regulamentando outras.

Diante do exposto, especificamente em relação aos hospitais brasileiros, estes continuam centralizando a prestação de cuidados à saúde, enfrentando o grave problema da ampliação da demanda social aliada à magnitude da recessão quantitativa e qualitativa de recursos humanos. Em contrapartida, na medida em que a população tem acesso às instituições hospitalares, na busca de recursos diagnósticos e/ou terapêuticos, medidas rigorosas de prevenção e de controle das infecções hospitalares devem ser tomadas para que não haja risco de se contraírem as respectivas infecções.

É oportuno considerar que, mesmo existindo as normatizações (dispositivos legais), os recursos químicos e/ou físicos, a infecção se faz presente nas atividades hospitalares, mesmo nos centros mais adiantados do mundo. Neste sentido, questionamos: "Será que o Brasil, onde a desigualdade social é alarmante, refletindo-se drasticamente nas condições de vida das pessoas, o problema das infecções hospitalares é ainda maior?"

\section{SITUAÇÃO ATUAL DAS INFECÇÕES HOS- PITALARES E PERSPECTIVAS DO FUTU- RO: CONSIDERAÇÕES FINAIS}

A realidade deste final de século é caracterizada, fundamentalmente, como a era do uso de procedimentos altamente sofisticados e invasivos, assim como do uso clínico dos antibióticos. Desde a introdução da penicilina $\mathrm{G}$ até o mais recente betalactâmico, considerado de quarta geração, vem se registrando uma pressão seletiva, causada pelo uso intenso, abusivo e indiscriminado de antimicrobianos, resultando em reações ecológicas entre os microrganismos que habi- tam os hospitais, com conseqüente seleção de espécies resistentes não só à droga administrada, mas, simultaneamente, a outras drogas, gerando expectativas sombrias para o futuro, se medidas urgentes não forem tomadas.

Neste contexto, [Rodrigues, $1997^{(10)}$ ] alerta-nos quanto à outras adversidades, por exemplo, o avanço dos fungos, os emergentes vírus Ebola e o Hantavírus, o gigante, até então adormecido, vírus da hepatite $\mathrm{C}$; e aquelas já conhecidas ou que estão por vir, as quais farão com que os conhecimentos, a energia, a paixão pela luta e a criatividade nos mantenham firmes no propósito de vencer.

Salientamos que, durante muito tempo, tem sido reconhecida a urgência em realizar estudos que possam, além de contribuir com a qualidade da assistência, reduzir o índice de infecção hospitalar, assim como o custo das hospitalizações. $\mathrm{O}$ combate às infecções hospitalares apresenta-se hoje como um problema complexo, suscitando polêmicas e antagonismos nos meios em que estas são detectadas.

Por outro lado, não podemos ficar alheios às novas propostas de assistência, as quais incluem: mudança do cuidado institucionalizado para o "desinstitucionalizado", evidenciado, por exemplo, através das altas hospitalares precoces, tratamentos ambulatoriais que substituíram longos dias de internação e hospital-dia. Lembramos que, quanto menor o período de internação, menores serão as chances de contaminação.

Embora a temática infecção hospitalar seja muito freqüente nos estudos, nas publicações e discussões de eventos científicos, ainda assim existem algumas questões que apontam lacunas ou a necessidade de estudos. Por esta razão, lançamos uma hipótese a ser confirmada ou refutada - $\mathrm{O}$ controle das infecções hospitalares deve ser iniciado antes da internação do paciente, através da melhoria das condições sanitárias, de programas efetivos de vacinação, da melhoria dos serviços básicos de saúde, no tratamento hábil das doenças, evitando-se internações desnecessárias e por tempo prolongado.

A necessidade premente de um sistema hospitalar onde haja uma combinação ótima dos recursos humanos, tecnológicos e financeiros tem sido reconhecida por todos os profissionais da saúde, e o controle da infecção hospitalar, em face da sua complexidade e relevância, tem merecido o desafio das equipes de saúde em qualquer parte do mundo. 
A infecção hospitalar é uma problemática que envolve uma pluralidade de ações, dentre elas, a aplicação de princípios e normas que cada profissional faz no exercício de suas atividades, a observação ativa, sistemática e contínua da ocorrência e da distribuição de tais infecções entre pacientes hospitalizados ou não. Quanto às condições que predispõem ao risco das infecções, essas, também, devem ser minuciosamente observadas com vistas à execução oportuna das ações de prevenção e controle ${ }^{(11)}$.

Assim, consideramos urgente o investimento em recursos humanos através de reuniões, debates, e reciclagens para alcançar o controle efetivo das infecções hospitalares. Sugerimos a inclusão do tema infecção hospitalar como conteúdo multidisciplinar, o que propiciará discussões e troca de experiências interinstitucionais. Reconhecemos, também, a importância de se criar a disciplina sobre infecção hospitalar, nos currículos de todos os cursos voltados à saúde.

Ainda temos que a informação e a educação continuam a ser a arma mais importante e disponível para o controle das infecções hospitalares.

Por tudo que foi exposto, deduzimos o quão é complicado prevenir as infecções hospitalares, lembrando que todas as omissões ou ações inadequadas colocam em risco não só os pacientes, como, também, os profissionais.

Neste contexto, um exemplo, já mencionado por nós, é a falta de adesão à lavagem das mãos, cuja importância foi epidemiologicamente comprovada desde o século XIX. Entretanto, ainda hoje é assunto de congressos, está presente em forma de alerta através de cartazes distribuídos nas instituições de saúde, comemora-se o dia mundial da lavagem das mãos, criam-se"slogans" promovem-se campanhas de conscientização, premia-se a melhor frase de sensibilização ao procedimento. No entanto, apesar de todos os investimentos em prol da lavagem das mãos, acreditamos que, ainda, será temática para o próximo milênio $^{(12)}$.

Existem outras negligências de técnicas básicas de assepsia, por exemplo, aquelas relacionadas às precauções universais ou precauções-padrão. Inquestionavelmente, a inadequação das medidas de proteção (por exemplo: uso de luvas, aventais, dentre outros), também, tem sido exaustivamente reconhecida e divulgada; ainda assim, sentimos dificuldade de adesão dos profissionais conforme recomendações preestabelecidas. Tudo nos leva a crer que estes tópicos, também, serão temas de estudos e de reflexões no futuro.

Não podemos ficar alheios ao grande avanço científico e tecnológico e se o controle desse arsenal, por um lado, representa melhores recursos para os profissionais de saúde na luta contra as infecções, por outro, traz a insegurança sobre quais são os mais adequados, quando buscamos, concomitantemente, qualidade da assistência e menor custo.

Sem refutar a importância inegável do avanço tecnológico para combater as infecções, há que se questionar a forma de sua utilização, uma vez, em grande parte, responsável pela ocorrência das referidas infecções, e já é assunto da literatura médica atual o impacto ambiental, fruto do consumo exagerado de produtos químicos, como, também, do descarte de artigos médico-hospitalares na natureza.

ANDRADE D \& ANGERAMI ELS. Reflections about cross infections in the transition to the third millenium. Medicina, Ribeirão Preto, 32: 492-497, oct./dec. 1999.

ABSTRACT: The present study has the main purpose of stimulating reflections of health professionals about cross infections. The authors present a synthesis of the relevant facts associated to the theme as well as of the regulations regarding the prevention and control of cross infections in Brazil. Following, they show and analyze the perspectives for the future. They point out the need for actions emphasizing human resources and materials as well as of understanding the problem in the broader context of the organization of the health system. They also give emphasis to some concerns: the indiscriminate use of antimicrobial products, unnecessary and long hospitalizations. Also, the awareness and change of behaviors are essential conducts in order to solve this important medical, social and economic problem.

UNITERMS: Cross Infection. Asepsis. Infection Control. 


\section{REFERÊNCIAS BIBLIOGRÁFICAS}

1 - MENDONÇA JS de. Mecanismo de resistência bacteriana e suas implicações. In: RODRIGUES EAC: MENDONÇA JS; AMARANTE JMB; ALVES FILHO MB; GRINBAUM RS \& RICHTMANN R. Infecções hospitalares prevenção e controle, Sarvier, São Paulo, p.561-570, 1997.

2 - LACERDA RA; JOUCLAS VMG \& EGRY EY. A face iatrogênica do hospital as demandas para o controle das infecções hospitalares. Atheneu, São Paulo, 1996.

3 - THORWARD J. $O$ século dos cirurgiões. Hemus, Rio de Janeiro, 1970.

4 - ALMEIDA LMQ \& CAVALCANTE RG. Atribuições do Serviço de Enfermagem Prevenção e Controle da Infecção hospitalar. Rev Paul Enf, São Paulo, 5:149-151, 1985.

5 - COUTO R C \& PEDROSA TMG. Epidemiologia aplicada ao controle das infecções hospitalares. In: COUTO RC; PEDROSA T M G \& NOGUEIRA JM. Infecção hospitalar Epidemiologia e controle. MEDSI, São Paulo, cap. 2, 1997.

6 - SPAULDING E.H. Chemical desinfection of medical and surgical materials. In: LAWRENCE, CA. \& BLOCK SS. Desinfection sterilization and preservation. Lea \& Febiger, Philadelphia, p. 517-531, 1968.

7 - OLIVEIRA C. Papel da enfermagem no controle da infecção hospitalar. Rev Paul Hosp 9/10: 216-222, set/out. 1982.
8 - BRASIL. Ministério da Saúde. Portaria n. 2616, Diário Oficial da União, Brasília, 12 de maio de 1998.

9 - BRASIL. Ministério da Saúde. Portaria no196 de 24 de junho de 1983. Diário Oficial da União, Brasília, 28 de junho de 1983.

10 - RODRIGUES EAC. Histórico das infecções hospitalares. In: RODRIGUES EAC; MENDONÇA JS; AMARANTE JMB; ALVES FILHO MB; GRINBAUM RS \& RICHTMANN R. Infecções hospitalares prevenção e controle, Sarvier, São Paulo, p.3- 28, 1997.

11 - SGARBI LPS \& CONTERNO LO. Estruturação dinâmica das comissões de controle de infecção hospitalar. In: RODRIGUES EAC ; MENDONÇA JS; AMARANTE JMB; ALVES FILHO MB; GRINBAUM RS \& RICHTMANN R.. Infecções hospitalares prevenção e controle, Sarvier, São Paulo, p.37- 41, 1997.

12 - ANGELO DA D.; OLIVEIRA SANTOS BM; BISPO AS \& LIMA MC. A limpeza de Unidade Terminal do Paciente no cotidiano de um hospital escola. In: Anais, VI Colóquio Pan-Americano de Investigação em Enfermagem, Ribeirão Preto, p.182, AEH31, Sessão de Pôsteres, 1998.

Recebido para publicação em 17/05/99

Aprovado para publicação em 30/11/99 